\section{Vitrectomy for phacolytic glaucoma in a patient with ectopia lentis et pupillae}

JD Rossiter, AH Morris, DE Etchells and MP Crick

\begin{abstract}
This case report highlights the successful management, by vitrectomy alone, of a case of chronic phacolytic glaucoma secondary to a dislocated hypermature lens in the vitreous of a patient with ectopia lentis et pupillae (ELP). The features and complications of ELP are discussed.

Eye (2003) 17, 243-244. doi:10.1038/

sj.eye. 6700302
\end{abstract}

Keywords: vitrectomy; phacolytic glaucoma; ectopia lentis et pupillae

We report the successful management of a case of chronic, uncontrolled phacolytic glaucoma secondary to a dislocated hypermature lens in the vitreous of a patient with ectopia lentis et pupillae (ELP). Using vitreo-lensectomy alone, good subsequent medical control of the intraocular pressure (TOP) was permitted.

\section{Case report}

A 51-year-old gentleman was first seen in the clinic in 1994 following referral for aphakic contact lenses. Previously, he had been seen elsewhere with 'congenitally dislocated lenses and an abnormality of the iris'. His visual acuity (VA) at presentation was $6 / 12$ right with

$+14.50 /-2.00 \times 30$ and $6 / 12$ left with $+14.50 /$ $-0.75 \times 180$.

In March 1999 he re-presented complaining of intermittent blurred vision in his left eye. The left VA was 6/12 and corneal epithelial oedema with a raised IOP of $37 \mathrm{mmHg}$ in the left eye was documented. This responded to treatment with guttae (g) timolol $0.5 \%$ b.d. and $g$ dorzolamide $2 \%$ b.d. Over the following 6 months, the left eye sustained two brief episodes of uveitis, complicated by elevated IOP. The uveitis responded to treatment with $g$ betamethasone q.d.s., but persisting raised IOP required the substitution of $g$ latanoprost o.n. for dorzolamide. He then remained stable until November 2001, when he presented to the eye casualty with acute blurring of vision in the same eye. His left VA was 6/18 and there was corneal epithelial oedema with an IOP of $57 \mathrm{mmHg}$. There was no evidence of anterior uveitis. Gonioscopy revealed open angles. A diagnosis of ELP was established, complicated by phacolytic glaucoma from a hypermature lens in the vitreous (Figure 1). The IOP responded to intravenous acetazolamide $500 \mathrm{mg}$ stat, oral acetazolamide $250 \mathrm{mg}$ t.d.s., and topical treatment consisting of $\mathrm{g}$ timolol $0.5 \%$ b.d. and g latanoprost o.n. G dexamethasone $0.1 \%$ q.d.s. was also administered. The IOP was normal the next day and the acetazolamide was discontinued. However, 6 days later the IOP measured $46 \mathrm{mmHg}$ in the left despite unchanged topical therapy. It was considered that the only definitive treatment would be to remove the exciting hypermature lens from the vitreous.

The problem of the ectopic poorly dilating pupil was solved by the use of standard iris hooks, which achieved an excellent view of the fundus. A posterior vitreous detachment was noted during the three-port pars plana vitrectomy, and the very dense hypermature lens was removed using a fragmatome. Heavy liquid was not used and no damage to the retina was seen. The IOP was $20 \mathrm{mmHg} 24 \mathrm{~h}$ postoperatively, and the pupil returned to its preoperative appearance. At the time of writing this report (3 months postoperatively), the IOP was $21 \mathrm{mmHg}$ with treatment of $\mathrm{g}$ timolol $0.25 \%$ b.d. and g latanoprost o.n.

\section{Comment}

ELP is a rare, inherited, congenital disorder characterised by typical ocular abnormalities but with no systemic manifestations. ${ }^{1-7}$ The
Bournemouth Eye Unit Royal Bournemouth Hospital

Castle Lane East Bournemouth, UK

Correspondence: AH Morris Bournemouth Eye Unit Royal Bournemouth Hospital

Castle Lane East Bournemouth, UK Tel: +44 1202303626 Fax: +44 1202704367 E-mail: ahcmorris@ doctors.org.uk 
Table 1 Reported findings in ELP

Poor visual acuity

Corneal astigmatism

Enlarged corneal diameter

Anterior uveitis

Elevated intraocular pressure

Prominent iris processes in anterior chamber angle

Small, poorly dilating oval or slit-like pupils

Persistent pupillary membranes

Iridodonesis

Iris transillumination

Bilateral ectopia of the lens and/or the pupil

Cataract

Microspherophakia

Iridohyaloid adhesions

Retinal detachment

homocystinuria. However, they carried out a vitreolensectomy combined with a trabeculectomy. With vitreo-lensectomy alone, our patient's IOP became controlled with medical therapy within $24 \mathrm{~h}$ and has remained so postoperatively.

We propose therefore that in such cases of chronic, uncontrolled phacolytic glaucoma, combined trabeculectomy is not always required, thus eliminating the potential complications of drainage surgery.

\section{References}

1 Townes PL. Ectopia lentis et pupillae. Arch Ophthalmol 1976; 94: 1126-1128.

2 Luebbers JA, Goldberg MF, Herbst R et al. Iris transillumination and variable expression in ectopia lentis et pupillae. Am J Ophthalmol 1977; 83: 647-656.

3 Cross HE. Ectopia lentis et pupillae. Am J Ophthalmol 1979; 88(3): 381-384.

4 Goldberg MF. Clinical manifestations of ectopia lentis et pupillae in 16 patients. Ophthalmology 1988; 95: 1080-1087.

5 Colley A, Lloyd IC, Ridgway A, Donnai D. Ectopia lentis et pupillae: the genetic aspects and differential diagnosis. J Med Genet 1991; 28: 791-794.

6 Cruysberg JRM, Pinckers A. Ectopia lentis et pupillae syndrome in three generations. Br J Ophthalmol 1995; 79: 135-138.

7 Byles DB, Nischal KK, Cheng H. Ectopia lentis et pupillae - a hypothesis revisited. Ophthalmology 1998; 105: 1331-1336.

8 Nelson LB, Maumenee IH. Ectopia lentis. Surv Ophthalmol 1982; 27(3): 143-160.

9 Smith GT, Vakalis AN, Brittain GP, Casswell AG. Vitrectomy for phacolytic glaucoma in a patient with homocystinuria. Am J Ophthalmol 1999; 128(6): 762-763. 